\title{
Selection of Saccharomyces cerevisiae Strains Applied to the Production of Prieto Picudo Rosé Wines with a Different Aromatic Profile
}

\author{
J.M. Álvarez-Pérez¹, M.L. Álvarez-Rodríguez ${ }^{1}$, E. Campo $^{2}$, L.E. Sáenz de Miera ${ }^{3}$, V. Ferreira ${ }^{2}$, P. Hernández-Orte², E. Garzón- \\ Jimeno $^{1}$, J.J.R. Coque ${ }^{1, *}$ \\ (1) Research Institute of Vineyards and Wine, University of León, 24071, León, Spain. \\ (2) Laboratory for Aroma Analysis and Oenology, Aragón Institute of Engineering, Department of Analytical Chemistry, \\ Faculty of Sciences, University of Zaragoza. 50009, Zaragoza, Spain. \\ (3) Genetics, Department of Molecular Biology, University of León, 24071, León, Spain.
}

Submitted for publication: January 2014

Accepted for publication: March 2014

Key words: Saccharomyces cerevisiae, yeast, wine, strain selection, industrial fermentation, wine aroma, Prieto Picudo

\begin{abstract}
The aim of this work was to select indigenous Saccharomyces cerevisiae strains based on a combination of genetic and aroma analyses to be used for inoculation in industrial fermentations and produce rosé wine with a different aromatic profile. A total of 118 indigenous strains of $S$. cerevisiae and one hybrid strain from five wineries and three different vintages were isolated from spontaneous microfermentations and genetically characterised according to the restriction fragment length polymorphism of their mitochondrial DNA (RFLP-mtDNA). From this group, 30 strains were subjected to phenotypic/oenological characterisation and, of these, nine were chosen as starters in wine fermentations due to their ability to ferment well and their appearance in consecutive vintages or in two or more wineries. Wines produced by these nine selected strains were aromatically and chemically characterised, revealing great differences in their sensory profiles. One of these strains (C9-I) showed the most complex aroma profile in the sensory characterisation, so it was selected to produce an industrial wine. A principal component analysis showed that the industrial wine produced was aromatically very different from several commercial wines produced by different wineries. In fact, their main aromatic attributes were not found in the commercial rosé wines selected for the sensory evaluation. The study shows that a combination of microbiological and chemical techniques can be an effective tool to improve the winemaking process to produce industrial wines with a distinctive organoleptic profile.
\end{abstract}

\section{INTRODUCTION}

Spontaneous wine fermentations are often unpredictable, resulting in undesirable traits that occasionally lead to spoilage. To reduce this risk, winemakers frequently use commercially available dried yeast strains to establish a homogeneous and high yeast population, which usually results in the development of rapid, reliable and wellcontrolled must fermentations (Pretorius, 2000). However, this practice often results in the inhibition of the indigenous S. cerevisiae strains (Constanti et al., 1997; Beltran et al., 2002). As a result, wines produced by using dry yeasts usually lack the distinctive properties that typify some local wines, resulting in a loss of the typical sensory properties and the characteristic profile of the wine of a specific wine region (Capello et al., 2004). This is particularly worrying when all winemakers in a particular region use a very limited number of commercial yeasts, which obviously results in the production of highly homogeneous wines, with a consequent reduction in aromatic complexity (Pretorius, 2000).

Prieto Picudo is an indigenous red grape variety of Vitis vinifera whose cultivation is geographically limited to southern León (in the Community of Castilla and León in northwest Spain). This region has a very long history of wine production due to its significant geographical location at the intersection of two important routes: the Roman Silver Way and the St. James Way. According to the Denomination of Origin (DO), wines produced with this grape variety are currently qualified as "Tierra de León," a DO that currently comprises 40 wineries. Although Prieto Picudo grapes are used to make red wines, they are much better known for their use in making rosé wines. The aroma profile of several Prieto Picudo rosé wines has recently been reported. Relatively high levels of ethyl esters, terpineols, nor-isoprenoids and polyfunctional mercaptans (Álvarez-Pérez et al., 2012) give

\footnotetext{
*Corresponding author: jjrubc@unileon.es [Tel.: +34987291811; Fax: +34987291409]

Acknowledgements: We thank all the wineries that provided us with musts from Prieto Picudo grapes: Bodegas Gordonzello S.A., Bodegas y Vinedos Pedro Casis, Vinicola Valmadrigal S.L., Cooperativa Vinícola Ribera del Cea and Cooperativa Los Oteros. J.M. Álvarez-Pérez was supported by an FPU fellowship from the Ministry of Education (Madrid, Spain). This work was partially supported by INIA (Madrid, Spain) and a Spanish MICYT (RM2006-00006-00-00 grant and AGL2007-65139/ALI project respectively)
} 
rise to their characteristically complex aroma. It is well established that yeast populations have a great influence on both the chemical composition of wines and their final aroma and flavour profile (for a review see Swiegers et al., 2005). Accordingly, the selection of indigenous yeast strains to be used as starters is considered the best approach in order to ensure the high typicality of wines, since these yeasts are better acclimated to the micro-area conditions of each wineproduction region, thus contributing to the maintenance of the typical sensory properties and characteristic profile of the wine from each area (Martini \& Vaughan-Martini, 1990; Nikolaou et al., 2006).

The selection of indigenous yeast strains is normally carried out in two sequential steps. First, isolated yeast colonies must be genetically analysed to discriminate between different species or strains. The most routinely used techniques are the sequencing of the D1-D2 domains of 26S rRNA (O'Donnel, 1993) and the analysis of the restriction fragment length polymorphism of the 5.8S ITS-rRNA region (Esteve-Zarzoso et al., 1999). Once a strain of $S$. cerevisiae has been identified, strain typing must be performed. This typing can be carried out by analysing electrophoretic karyotypes using pulsed-field gel electrophoresis (Degre et al., 1989), restriction fragment length polymorphism of mitochondrial DNA (RFLP-mtDNA) (Querol et al., 1992a; López et al., 2001), or by different PCR-based techniques (Legras \& Karst, 2003; Gallego et al., 2005). Second, an additional analysis is required in order to select those strains with better oenological properties, especially those that are relevant to the fermentation process, such as ethanol tolerance and production, high fermentation capability, and volatile acidity production, among others (Pretorius, 2000). Nonetheless, other criteria can also be used, such as the capacity to dominate a spontaneous fermentation (Versavaud et al., 1995). Surprisingly, a recent survey revealed that all of the wineries of the DO Tierra de León use just five different dry yeast strains to produce rosé wines (see Table S1, Supporting information). Accordingly, all the wines produced show a very similar aromatic profile. The main aim of this study was to demonstrate that, based on a careful selection of yeasts to be used in industrial applications, it is possible to produce wines with a markedly different aromatic profile that consumers appreciate and that would be clearly distinguishable from the industrial wines currently elaborated in this region.

\section{MATERIALS AND METHODS}

\section{Yeast isolation from spontaneous wine fermentations}

Spontaneous fermentations were carried out during three different vintages for each winery (between 2005 and 2009) using 15 batches (five samples per year) of natural grape juice (Prieto Picudo variety) provided by five different wineries of DO Tierra de León: Gordonzello S.A., Cooperativa Los Oteros, Bodegas Pedro Casis, Cooperativa Vinícola Ribera del Cea, and Vinícola Valmadrigal. Fermentations were conducted at room temperature $\left(21\right.$ to $\left.24.5^{\circ} \mathrm{C}\right)$ from $2 \mathrm{~L}$ of grape juice in $3 \mathrm{~L}$ Pyrex bottles fitted with an air-lock system to release the $\mathrm{CO}_{2}$ produced. Fermentations were monitored daily by measuring the weight loss of the bottles until the fermentation was complete (constant weight). Aliquots of
$0.1 \mathrm{~mL}$ from serially diluted finished wines samples were plated on WL nutrient agar (Scharlau, Barcelona, Spain) plates supplemented with $150 \mu \mathrm{g} / \mathrm{mL}$ chloramphenicol (Sigma-Aldrich, Madrid, Spain). Plates were incubated at $30^{\circ} \mathrm{C}$ for 2 to $3 \mathrm{~d}$ and those containing 20 to 200 colonies were examined. Representative colonies (60 per winery and vintage) were randomly selected for genetic typing. Clones were named using a letter to indicate the winery from which they were isolated (C: Pedro Casis; G: Gordonzello; P: Cooperativa Los Oteros; R: Cooperativa Vinícola Ribera del $\mathrm{Cea}$; and V: Vinicola Valmadrigal), followed by a number indicating the vintage, and a final consecutive number representing the analysed clone (i.e. G7/7 corresponds to clone 7 isolated in the Gordonzello winery from the 2007 vintage). Each strain of $S$. cerevisiae was named by using Roman numerals (i.e. G7-VII corresponds to the strain VII isolated from the 2007 vintage of the Gordonzello winery,) according to its genetic typing.

\section{Characterization of yeast species}

Yeast identification was carried out by RFLP analysis of the 5.8S-ITS-rRNA region amplified by using ITS1 and ITS4 primers (White et al., 1990) and confirmed by sequencing the D1-D2 regions of 26S rDNA using the NL-1 and NL-4 primers (O'Donnel, 1993). Total yeast DNA was isolated according to the protocol developed by Querol et al. (1992b).

\section{Genetic typing of Saccharomyces strains}

S. cerevisiae strain typing was performed by RFLP-mtDNA analysis with AluI restriction enzyme (Querol et al., 1992a). The RFLP profiles were compared using the InfoQuest FP software package (Bio-Rad, Hercules, CA). Dendrograms (UPGMA type) were processed according to DICE's coefficient of similarity (DICE algorithm), allowing a size tolerance of $0.72 \%$ (empirically calculated). When the similarity between two or more strains was equal to or greater than $95 \%$, additional comparisons were made by using Hinfl and RsaI restriction enzymes to confirm the previous prediction. The commercial dry yeast strains used by the wineries (Table S1, supporting information) were analysed in the same way and their RFLP-mtDNA patterns were compared in order to discriminate between commercial and indigenous yeasts.

\section{Experimental microfermentations with selected strains}

Microvinifications were conducted in triplicate in $500 \mathrm{~mL}$ bottles containing $350 \mathrm{~mL}$ of grape must sterilised by filtration through $0.22 \mu \mathrm{m}$ filters (Millipore, Billerica, USA), prior to adding selected Saccharomyces strains. Each microvinification was inoculated with one $\mathrm{mL}$ of a yeast pre-inoculum $\left(\mathrm{OD}_{600}=1\right)$ from overnight cultures. Microfermentations were carried out at $20^{\circ} \mathrm{C}$ and monitored by measuring the loss of weight, as described above. Once fermentations were completed, yeast cells were removed by centrifugation (5 min/4 $000 \mathrm{rpm}$ ). Samples for quantitative analysis were stored at $-20^{\circ} \mathrm{C}$ until analyses were performed. Samples used for sensory descriptive analysis were stored in glass bottles at $4^{\circ} \mathrm{C}$ under nitrogen atmosphere. 
Analysis related to wine yeast fermentation performance The analysis of glucose, fructose, glycerol, ethanol and acetic acid in wines was performed by HPLC using an Agilent 1200 series (Agilent Technologies, Santa Clara CA, USA) chromatograph equipped with a HyperREZ XP Carbohydrate $\mathrm{H}^{+}$column $(8 \mu \mathrm{m}$ particle size, $300 \times 7.7 \mathrm{~mm})$ and a HyperREZ XP carbohydrate $\mathrm{H}^{+}$Guard pre-column (Thermo Scientific, Waltham, USA), maintained at $50^{\circ} \mathrm{C}$. Samples were filtered using $0.45 \mu \mathrm{m}$ cellulose acetate filters (Costar, Washington DC, USA), and diluted (wine, 1:5; grape juices, 1:25) prior to analysis. A refraction index detector (RID) (positive polarity) at a flow rate of $0.8 \mathrm{~mL} / \mathrm{min}$ with $4 \mathrm{mmol} / \mathrm{L} \mathrm{H}_{2} \mathrm{SO}_{4}$ as mobile phase (injection volume $25 \mu \mathrm{L}$ ) was used to detect glucose, fructose, glycerol and ethanol, whereas acetic acid was detected using a variable wavelength (VWL) detector $(210 \mathrm{~nm})$. Quantification of products was performed by measuring area peaks and comparing them to calibration curves obtained with standard products. One-way analysis of variance (ANOVA) was carried out with SPSS to determine the influence of the "yeast used" factor on glucose, fructose, glycerol, ethanol and acetic acid levels. The fermentative capability was determined by measuring the amount of reducing sugars in wines using the official method of the Office International de la Vigne et du Vin (OIV, 1979). The rate of sugar consumption was obtained from the linear regression equation of the log part of the curve depicting the amount of reducing sugars as a function of time. Data were fit with the re-parameterised Gompertz equation proposed by Zwietering et al. (1990). The tolerance level to ethanol was checked as reported by Arroyo-López et al. (2010). Growth rate at a low temperature was assayed in microtitre plates. Each well, containing $200 \mathrm{~mL}$ of YNB medium (Difco Laboratories In., Detroit, USA), was inoculated with $10 \mathrm{~mL}$ of a yeast suspension of $\mathrm{OD}_{600}=1$. Plates were incubated at $15^{\circ} \mathrm{C}$ and growth was estimated by measuring absorbance $\left(600_{\mathrm{nm}}\right)$ every $12 \mathrm{~h}$. The growth curves, after normalisation, were fitted to a non-lineal model (modified Gompertz equation). The slope of the curve indicated the behaviour of yeast analysed under low temperature conditions. The killer phenotype was determined by comparison to reference strains: the killer strains 1101 (K1), EX73 (K2), EX198 (Klus) and F182 (K28), together with killer-sensitive strains $5 X 47$ and EX33 (free of RNA viral particles). Most of the strains were kindly provided by Dr Ramírez (RodríguezCousino et al., 2011). Killer sensitivity was assayed by plating the test strain on YEPD-MB agar (Lopes et al., 2006), and then streaking the reference killer strains onto the surface of each plate and incubating at 18 to $20^{\circ} \mathrm{C}$ for 3 to $5 \mathrm{~d}$. Killer activity, on the other hand, was assessed by plating reference strains and streaking the test yeast over them (Sangorrín et al., 2001).

\section{Elaboration of an industrial wine}

An industrial trial was done with an autochthonous yeast. Three different batches of wine were elaborated from $2500 \mathrm{~kg}$ of Prieto Picudo grapes in Bodegas Pedro Casis according to the same protocol used by the winery to produce other rosé commercial wines. The only difference was the inoculum method used. Must (with an initial density of $1100 \mathrm{~g} / \mathrm{L}$, equivalent to a sugar content of $236 \mathrm{~g} / \mathrm{L}$ and a maximum likely alcohol content of $13.9 \%$ ) was inoculated by adding a pure culture of C9-I yeast strain. Yeast cells were grown in YPD liquid medium (Lodder, 1970) at $25^{\circ} \mathrm{C}$ for $48 \mathrm{~h}$ at $200 \mathrm{rpm}$ in an orbital incubator. Cells were harvested by centrifugation and washed twice with a volume of $0.9 \%$ sterile saline solution. Finally, the yeast biomass was suspended in a suitable amount of grape must to achieve a final concentration of $10^{8}$ cells $/ \mathrm{mL}$. Fermentation was initiated by adding fresh yeast biomass to the grape must contained in three $500 \mathrm{~L}$ stainless steel fermentation tanks to obtain an initial concentration of $1.5 \times 10^{5}$ yeast cells $/ \mathrm{mL}$ in each one. Fermentation was conducted at $15^{\circ} \mathrm{C}$ until the must reached a density of $0.993 \mathrm{~g} / \mathrm{L}$, which correspond to almost sugar completion.

\section{Sensory evaluation}

Sensory evaluation (only orthonasal) of the experimental and industrial wines was carried out by a panel of nine judges (six women and three men), members of the laboratory staff with a long history of experience in this type of analysis. After four $1 \mathrm{~h}$ training sessions, the panellists scored each experimental wine using nine sensory descriptors previously agreed upon (fresh, dried and exotic fruit, vegetal, aromatic herbs, toasty, sweet, spicy and reduction) as the most appropriate to describe the wine samples, as previously reported (ÁlvarezPérez et al., 2012). The data were processed according to the formula developed by Dravnieks (1985) to calculate the modified frequency $[\mathrm{MF}(\%)]$ for every aroma attribute.

\section{Analysis of volatile compounds by gas chromatography}

Analysis and quantification of the major volatile compounds in the wines were performed according to the method developed by Ortega et al. (2001), with some adjustments (Álvarez-Pérez et al., 2012). The analysis of minor compounds present in the wine aroma was carried out using the method proposed and validated by López et al. (2002), with modifications introduced by Loscos et al. (2007).

\section{Statistical analysis}

Principal components analysis (PCA) was performed using Community Analysis Package 2004 software, version 3.11 (CAP III) (PISCES Conservation Ltd., Lymington, UK). General statistical analysis, such as ANOVA, was carried out by SPSS software v. 15.0 (Chicago, Illinois, USA).

\section{RESULTS}

\section{Genetic analysis of isolated indigenous $S$. cerevisiae strains}

A total of 900 yeast colonies were analysed (180 clones from every winery corresponding to three different vintages: 60 clones per vintage). RFLP analysis of the 5.8S-ITS-rDNA region showed that 898 clones exhibited restriction patterns typical of $S$. cerevisiae strains for the restriction endonucleases HaeIII, AccI and ScrFI. Two clones, G6/2 (clone 2 isolated from Gordonzello winery, 2006 vintage) and P5/7 (clone 7 isolated from Cooperativa Los Oteros, 2005 vintage) showed abnormal restriction patterns with the enzyme HaeIII (Fig. 1). A detailed analysis of clone G6/2, consisting of the amplification and restriction of genes MET6, OPY1, CYR1, GSY1 and CAT8 (González et al., 2006), and the subsequent 
sequencing of the 5.8S-ITS region, D1-D2 domains of $26 \mathrm{~S}$ rRNA and regions of BRE5 and EGT2, confirmed that this clone corresponded to a typical $S$. cerevisiae strain, but that it was carrying a point mutation in the 5.8S-ITS region that generated a new HaeIII restriction site. This point mutation resulted in the splitting of the typical $175 \mathrm{bp}$ HaeIII band into two new bands of $145 \mathrm{bp}$ and $30 \mathrm{bp}$ (see Fig. 1). A detailed analysis of clone P5/7 was also performed: restriction analyses of 35 nuclear genes and sequencing of the MET6 nuclear gene and the COX2 mitochondrial gene confirmed that this clone was a $S$. cerevisiae $\mathrm{x} S$. kudriavzevii hybrid yeast (clone named PB7 in Peris et al. 2012). The RFLP-mtDNA analysis led us to detect 119 different strains (Fig. S1, Supporting information), not counting the commercial dry yeasts used by the different wineries. Most of the strains ( 110 or $92.4 \%$ ) were exclusively from a single winery and could be considered as "indigenous strains of winery"; exactly 31 strains were exclusively from Ribera del Cea, 29 from Cooperativa Los Oteros, 19 from Gordonzello, and 16 and 15 respectively from the Vinícola Valmadrigal and Pedro Casis wineries. A very reduced number of strains (eight strains, corresponding to $6.8 \%$ ) were detected in two different wineries, and one strain (C9-II) was present in four out of the five analysed wineries (Fig. S1, highlighted in the shaded box). Monospecific $S$. cerevisiae yeast populations were always composed of several genetically distinct strains that grew simultaneously, of which one to three strains were predominant, since together they represented more than $50 \%$ of the total yeast population. For example, in the case of the Pedro Casis winery, a total of nine different strains were detected in the 2006 vintage. Two of these strains were predominant, since they represented $84.22 \%$ of the total population (strain C6-II represented $70.18 \%$ and strain C6-III 14.04\%). Similar results were obtained for the rest of the wineries and vintages analysed. Commercial dry yeast used by the wineries was rarely found in spontaneous fermentations carried out and, when detected, they usually represented (with the exception of the 2007 and 2008 vintages from the Vinicola Valmadrigal winery) a minor percentage with respect to the total yeast population (Table S2, Supporting information).

\section{Phenotypic and oenological characterisation of selected strains}

Given the fact that a high number of Saccharomyces strains were isolated (119), criteria for further phenotypic and oenological analyses were established. Thus, in a first phase, we preselected those strains that fit the next criteria: strains dominating a fermentative process and strains isolated for two or three consecutive years in the same winery, since these could represent those strains more adapted to both the conditions of wine production and the chemical composition of musts (Versavaud et al., 1995). We also selected strains isolated in two or more wineries, since they could be representative of a particular oenological region or "terroir" (Versavaud et al., 1995). Using this criteria, 30 different strains were selected for further oenological characterisation (parameters estimated are listed in Table 1). A detailed analysis of the data matrix obtained (data not shown) led us to select the potential nine best strains (according to oenological

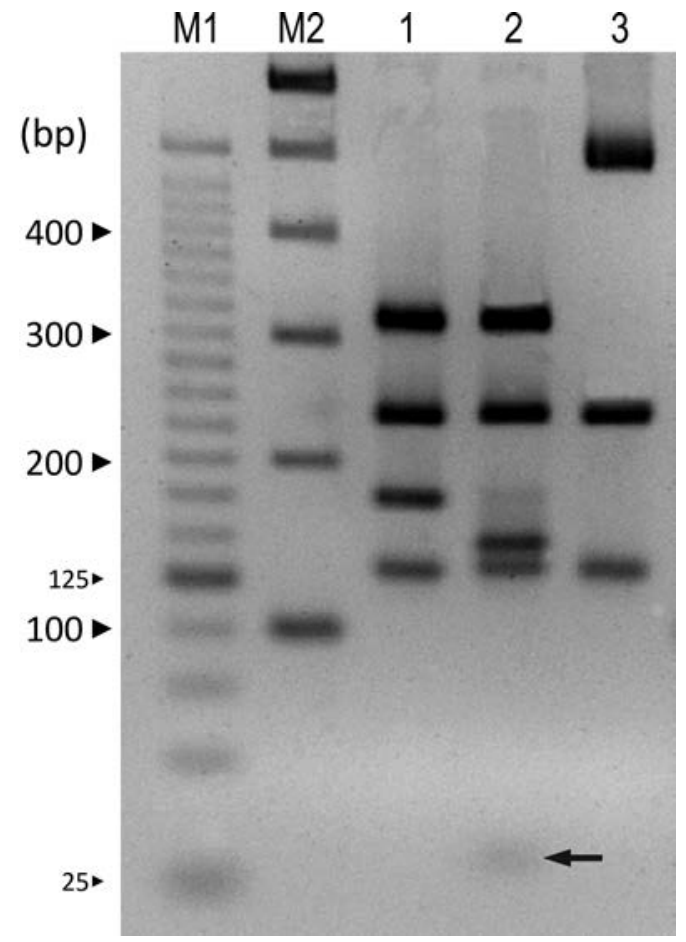

FIGURE 1

RFLP analysis I of the 5.8S-ITS region of different yeasts, isolated from spontaneous fermentations, with the HaeIII endonuclease. Lanes: M1, 25 bp ladder (Invitrogen); M2, $100 \mathrm{bp}$ ladder (Invitrogen); 1, G6/25 clone corresponds to a typical $S$. cerevisiae strain (bands of 325, 230, 175 and $125 \mathrm{bp}) ; 2, \mathrm{G} 6 / 2$ clone exhibited an abnormal restriction pattern due to a point mutation generating a new HaeIII site that resulted in the splitting of the typical $175 \mathrm{bp}$ HaeIII band into two new bands of $145 \mathrm{bp}$ and $30 \mathrm{bp}$ (indicated by a black arrow); 3, P5/7 clone also exhibited a non-typical restriction pattern that corresponded to a $S$. cerevisiae $\mathrm{x} S$. kudriavzevii hybrid yeast (Peris et al., 2012).

parameters like fermentation rate, specific growth rate at $15^{\circ} \mathrm{C}$, low acetic acid and glycerol production, and so on) (Table 1), on which we performed additional aromatic and chemical characterisation. The acetic acid levels ranged from 465 to $1470 \mathrm{mg} / \mathrm{L}$ among the experimental wines. Some researchers have reported acceptability levels for this compound of between 700 to 1100 , depending on the style of wine (Corison et al., 1979), whereas other studies have shown that acetic acid above $450 \mathrm{mg} / \mathrm{L}$ can depress the perception of wine fruitiness (Campo et al., 2005). Although two of the wines (G7-III and P5-XI) had higher levels of this compound, they were not considered by the experienced testers as unpleasant in the sensory evaluation performed. In any case, the final level of acetic acid in these wines diminished their final score and they accordingly were not selected for industrial trials. In this way, two strains from Bodegas Pedro Casis (C9-I and C9-II) were selected. C9-I was the dominant strain in the three vintages analysed $(70.18 \%$, $56.70 \%$ and $60.00 \%$ in the 2006, 2008 and 2009 vintages respectively), whereas the C9-II strain (although a minority) could also be isolated routinely (representing 1.75\%, 5.00\% and $6.67 \%$ respectively in the same three vintages analysed). 
It is interesting to note that this last strain was also isolated in another three of the five wineries analysed (see shaded box in Fig. S1). Strains G7-III and G7-XIV (Bodegas Gordonzello) were detected in all three vintages analysed (2005, 2006 and 2007), although they never behaved as dominant strains. The first one was also detected in Vinícola Valmadrigal, but in a previous vintage (named strain V6-III) (see Fig. S1).

Two of the strains selected were isolated from the Ribera del Cea winery: strain R7-I was the dominant one in the 2007 vintage $(43.33 \%)$ and it was also detected in the 2008 vintage $(10.00 \%)$, whereas strain R8-II behaved as the dominant strain in the 2008 vintage $(45.00 \%)$. Strains V7-III and V8-XVII (from the Vinicola Valmadrigal winery) were classified as minority strains although they were isolated in two different vintages: V7-III was detected in the years 2006 and 2007 (10.34\% and $1.67 \%$ respectively), whereas the V8-XVII strain was detected in both the 2007 (1.67\%) and $2008(1.67 \%)$ vintages. Finally, although it was a minor strain and only detected in the 2005 vintage, the $S$. cerevisiae $\mathrm{x}$ S. kudriavzevii hybrid strain P5-XI (clone P5/7) was selected, since Saccharomyces hybrids represent one of the most interesting mechanisms involved in the adaptation to specific fermentation conditions that could result in interesting oenological properties (González et al., 2006; Querol \& Bond, 2009). Thus, from the 30 preselected strains, we chose nine strains that showed superior performance for the different parameters measured (listed in Table 1) according to the comparison between each single strain against the averaged values of the 30 preselected strains (Table 1). It was remarkable that all of the strains grew well at low temperatures, although the hybrid (P5-XI) strain exhibited the best performance for this parameter (see Table 1). The analysis of killer phenotypes yielded mixed results, since different phenotypes were detected (see Table 1), including a strain (C9-II) with a very infrequent killer characteristic that could not be determined. In fact, C9-II behaved like a killer strain, although exhibiting sensitivity to K1 and K2 toxins. When its associated genetic material (dsRNA) was analysed (data not shown), we could detect the L-A particle, but no toxin-encoding satellite of dsRNA was isolated. The experimental wines produced in microvinifications by using the selected $S$. cerevisiae (and also the hybrid) strains were analysed by HPLC to measure the levels of sugars, glycerol, ethanol and acetic acid (Table 1).

\section{Sensory profiles of the experimental wines}

The results of the sensory descriptive analysis of the experimental wines are shown in Fig. 2. Arrows, representing the projection of the sensory variables on the plane formed by principal component 1 (PC1) and principal component 2 (PC2), explained $63.81 \%$ of the total variance. PC1 (41.49\% of the variability) compares the sweet and fruity characteristics (fresh and exotic) to the reduction and dried fruit attributes. PC2 $(22.12 \%)$ is mainly defined by descriptors such as aromatic herbs, spicy and vegetal. Fig. 2 also encompasses a projection of the nine experimental wines in a bi-dimensional plot. Wines were regularly located in the various quadrants of the PCA plot, scattered all over the map, indicating a high variation between wine samples. The closest aromatic attribute (represented by arrows) to a wine (represented by squares) indicates its main aromatic profile. Some of these profiles deserve special attention. For example, the C9-II wine (see Fig. 2, right lower quadrant) obtained the highest scores for exotic/fresh fruit and sweet nuances, which are highly appreciated by most consumers of rosé and young red wines. A very different profile was exhibited by sample R8-II (left upper quadrant), which generated clear vegetal attributes. The wine produced by the hybrid strain (P5-XI) showed the highest reduced notes among all the wines analysed.

\section{Chemical quantitative analysis of wine aroma volatiles}

Quantitative data from the volatile compounds analysed in the experimental wines made with the selected yeasts are presented in Table 2. A total of 64 compounds from different aromatic families were determined; the ester and acetate family had the largest group of components. The wine that contained the highest amount of esters was C9-II, due to its predominant "exotic fruits" character. This wine also presented the highest level of 2-phenylethyl acetate (1 $946 \mu \mathrm{g} / \mathrm{L}$ ) and had a marked sweet odour, described as a mix of vanilla and caramel aromas, obtaining the maximum score for this descriptor (Fig. 2). Quantitatively, alcohols were the largest group of compounds analysed. Alcohols with six carbon atoms (1-hexanol and Z-3-hexan1-ol) can provide vegetal and herbaceous nuances to wine. The R8-II wine exhibited high concentrations of these compounds (1 733 and $253 \mu \mathrm{g} / \mathrm{L}$ respectively), which coincide with its principally vegetal character (see Fig. 2). However, the P5-XI wine (produced with the S. cerevisiae $\mathrm{x}$ $S$. kudriavzevii hybrid yeast) presented slightly higher values (1 $986 \mu \mathrm{g} / \mathrm{L}$ of 1-hexanol and $321 \mu \mathrm{g} / \mathrm{L}$ of Z-3-hexen-1-ol) of these compounds, although this wine exhibited a principal reduction nuance that masked the herbaceous notes (see the relative position of this wine in Fig. 2). Other families of compounds quantified were terpenes and norisoprenoids. Great variability was obtained when comparing different wines. Thus the P5-XI wine (produced with the hybrid yeast) presented high values for these compounds (linalool, $\alpha$-terpineol, $\beta$-citonellol and geraniol). Some variability in norisoprenoid compounds ( $\beta$-damascenone and $\beta$-ionone) was also noted. Compounds in the volatile phenols family were not detected in high concentrations. The P5-XI wine exhibited the highest grossing values for some of these volatile phenols (see Table 2), such as o-cresol, eugenol and 2,6-dimethoxyphenol. We also found significant levels of some lactones in our wines, even though they never were in contact with oak wood.

\section{Comparison of the different sensory profiles in industrial wine and several commercial wines}

An industrial wine (IW) was crafted in triplicate using the C9-I strain since, according to the panel of tasters and the chemical quantitative results, this strain had the most aromatically and complex profile. These wines exhibited the following analytical parameters: ethanol, $12.62 \pm 0.19 \%$ vol.; $\mathrm{pH}, 3.23 \pm 0.08$; acetic acid, $0.48 \pm 0.06 \mathrm{~g} / \mathrm{L}$; glucosefructose residue, $4.79 \pm 0.23 \mathrm{~g} / \mathrm{L}$; total reducing sugars, 5.6 $\pm 0.4 \mathrm{~g} / \mathrm{L} ; \mathrm{SO}_{2}, 55.0 \pm 6.0 \mathrm{mg} / \mathrm{L} ; \mathrm{L}-$ malic, $1.17 \pm 0.09 \mathrm{~g} / \mathrm{L}$. Yeast cells were randomly isolated in the middle and at the 


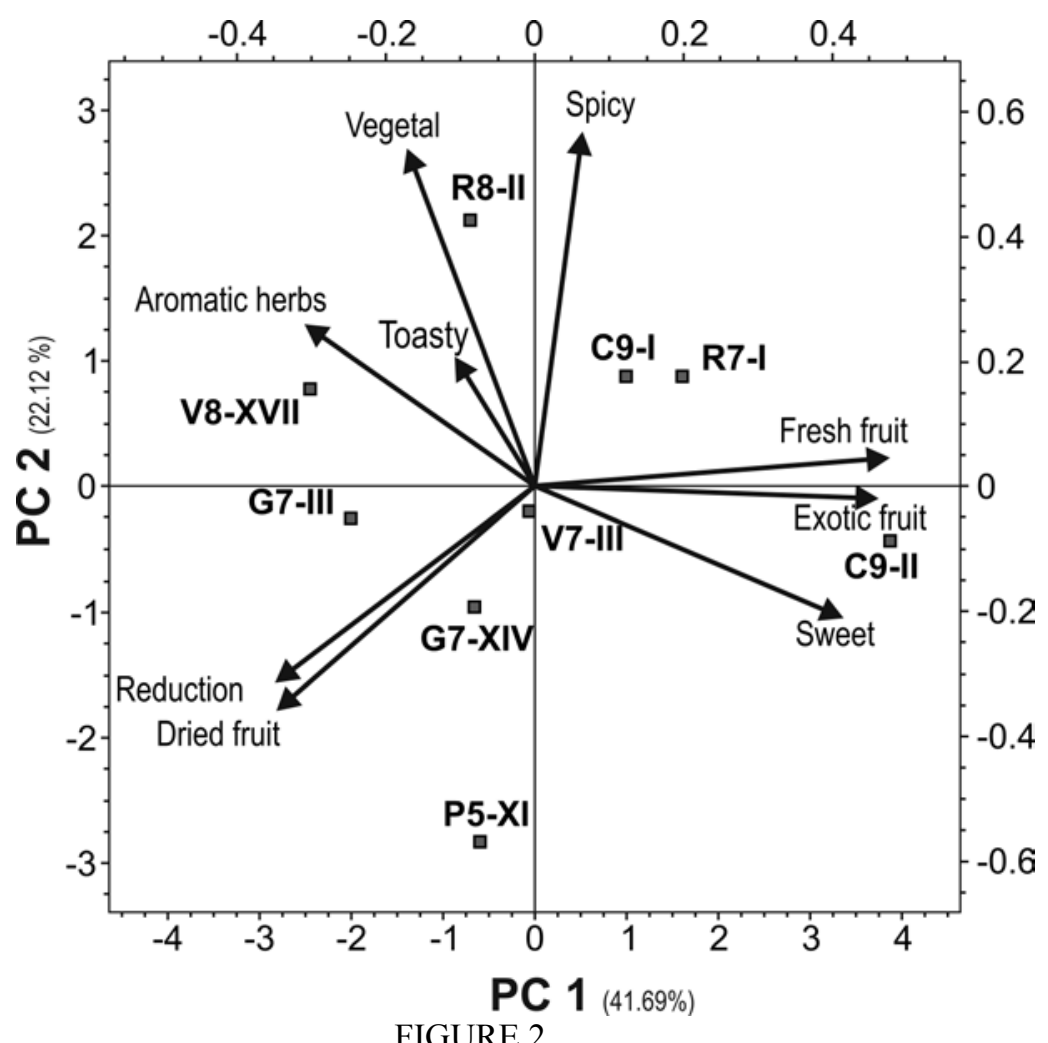

FIGURE 2

Principal component analysis (PCA) of the nine wines fermented with the selected strains. In the plot, the arrows designate the correlation circle with the sensory descriptors, while squares represent the projections of wines in the indicated PCA plot. Principal components (PC) 1 and 2 explain $41.49 \%$ and $22.1 \%$ of the total variance respectively. The scale of variables (sensory descriptor) is shown at the top and right, whereas the scale for wines is shown at the bottom and left. Values represented are the average for the three microvinifications performed with every strain. Statistical analysis of the modified frequency values obtained for every aroma attribute did not yield significant difference between the three replicates.

end of fermentation, and 40 clones were analysed by RFLPmtDNA. All the clones were unambiguously identified as the C9-I strain, indicating that the implantation of the inoculated yeast in the must had been complete, and that the wine therefore had been produced by the selected strain. The sensory profile of the industrial wine (IW) was evaluated in comparison to that of eight commercial Prieto Picudo rosé wines (CW1 to CW8) elaborated with different commercial strains (Table S1, Supporting information). The results of the sensory descriptive analysis are shown in Fig. 3, which represents three PCA plots, each of them formed from two principal components. The decay graph shows the total variance explained by each principal component. Only the first three variables were taken into account for this study, since together they explain $78.56 \%$ of the total variance. The PC1-PC2 plot explained $60.06 \%$ of the total variance, whereas the PC1-PC3 and PC2-PC3 pairs explained 58.12\% and $38.94 \%$ respectively.

The projections of eight commercial wines (gray squares, CW1 to CW8), together with the industrial wine (black squares, IW) were included in all plots. The aromatic profile of the IW was very different from that of the $\mathrm{CW}$, as can be seen by its location on the PCA plots, far from any CW. In the PC1-PC2 plot, IW is located in an area dominated by vegetal, toasty, sweet and aromatic herb attributes, along with those of exotic fruits, mainly defined by PC1 (39.62\% of the total variance). In the PC1-PC3 plot, a similar result was also obtained, since IW is located near toasty and sweet attributes. The result shown in the PC2-PC3 plot sheds more light on the aromatic profile, since the IW was located solely in an area dominated by toasty and sweet variables. The data presented confirm that IW is clearly distinguishable from $\mathrm{CW}$ when analysed by its aromatic profile.

\section{DISCUSSION}

The ultimate aim of the current study was to select indigenous $S$. cerevisiae strains for use in industrial controlled fermentations in order to produce wines with a distinctive aromatic profile that differentiate them from the commercial and very similar wines already present in the market. Yeasts were isolated from finished fermentations, since it was assumed that predominant strains can be considered the most adapted to both the chemical must composition and the technological conditions of wine production (Beltran et al., 2002; Nikolaou et al., 2006; Lopandić et al., 2008). Great heterogeneity was detected in the yeast populations of the five wineries analysed, as previously reported by other authors (Versavaud et al., 1995; Nikolaou et al., 2006; Lopandić et al., 2008) in different wine regions. In fact, most of the strains detected (110 or $92.4 \%$ ) had a single source, since they were exclusively isolated from any of the five analysed cellars. This fact has a potential industrial interest, 


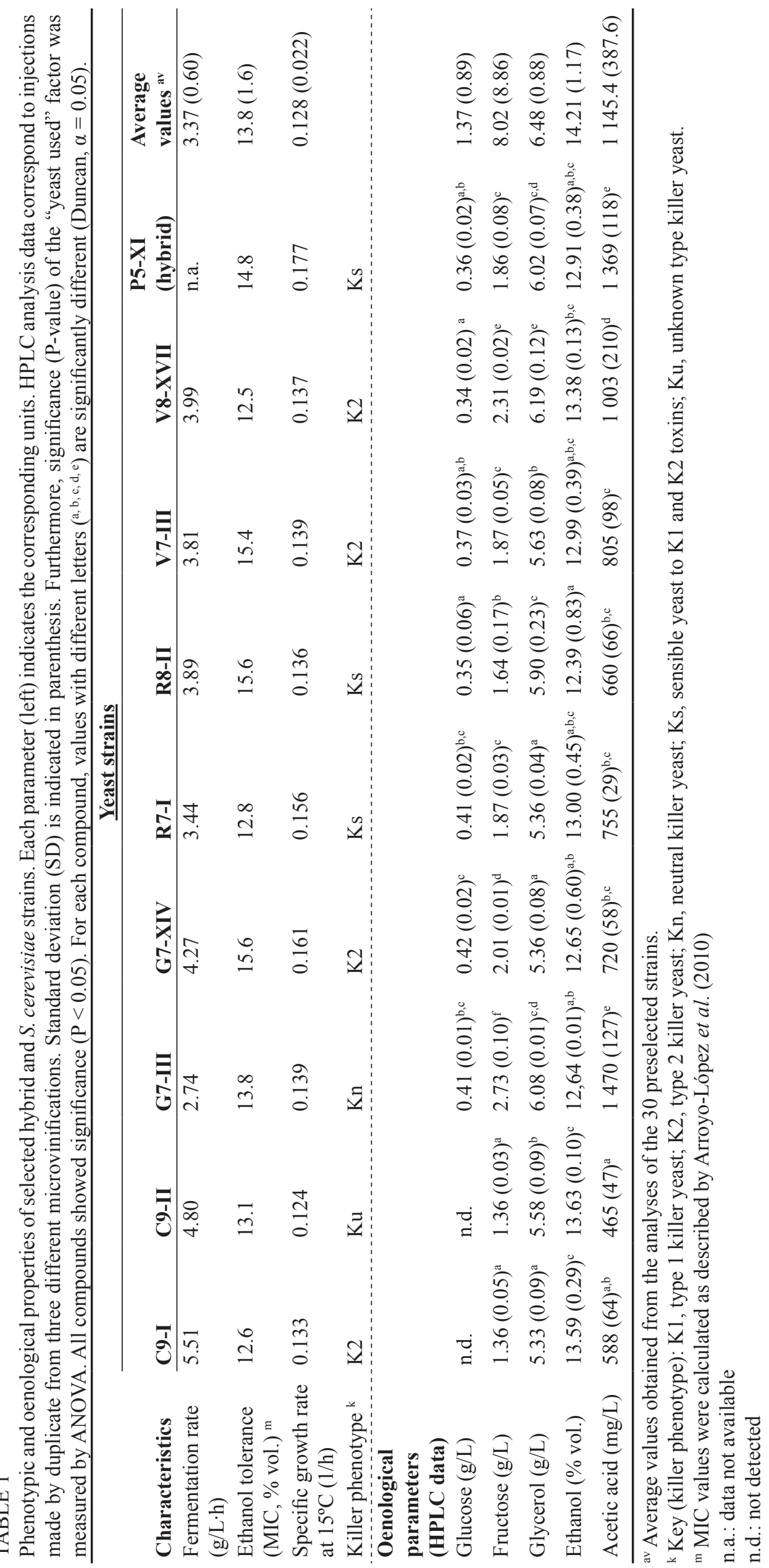




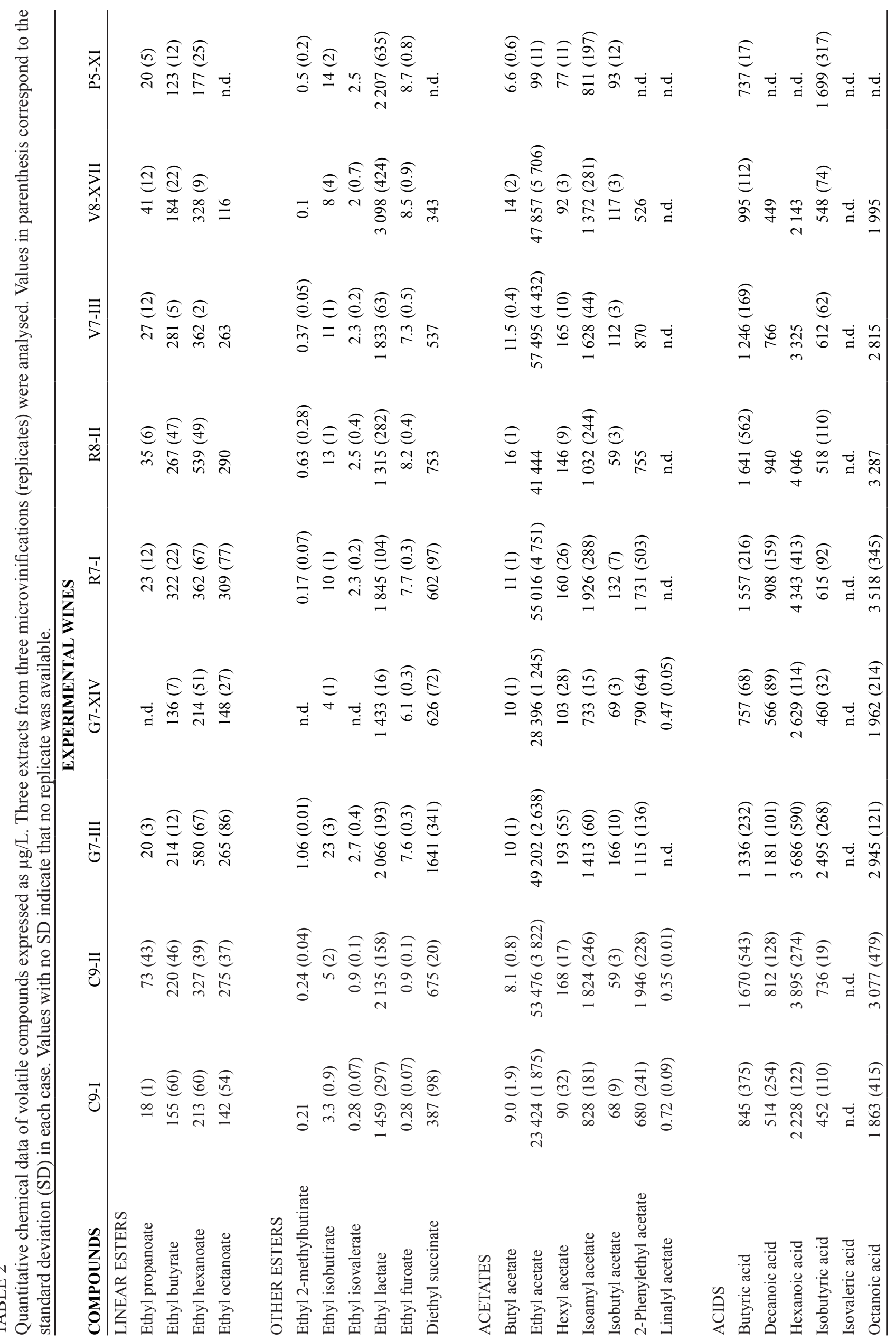




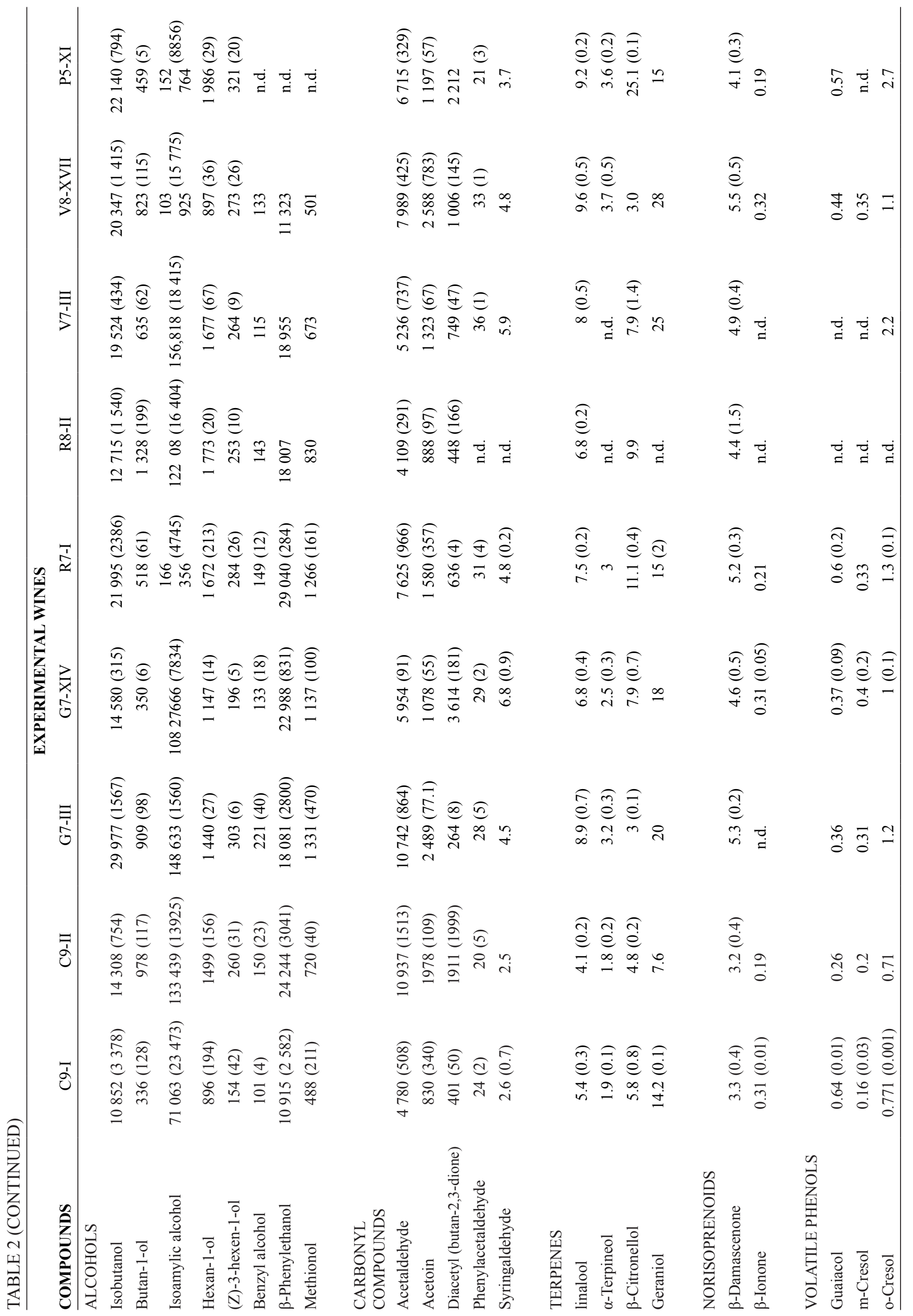




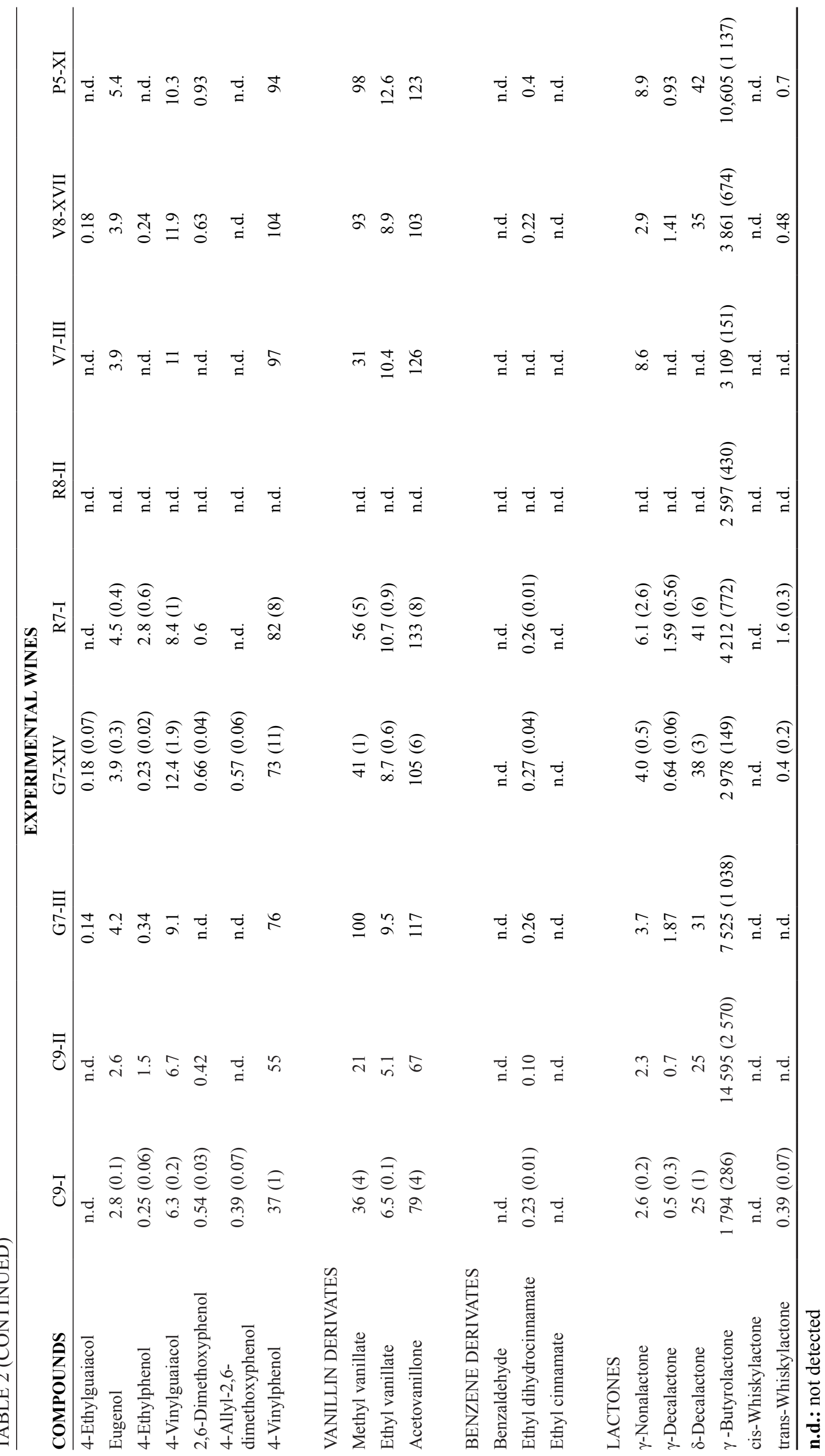




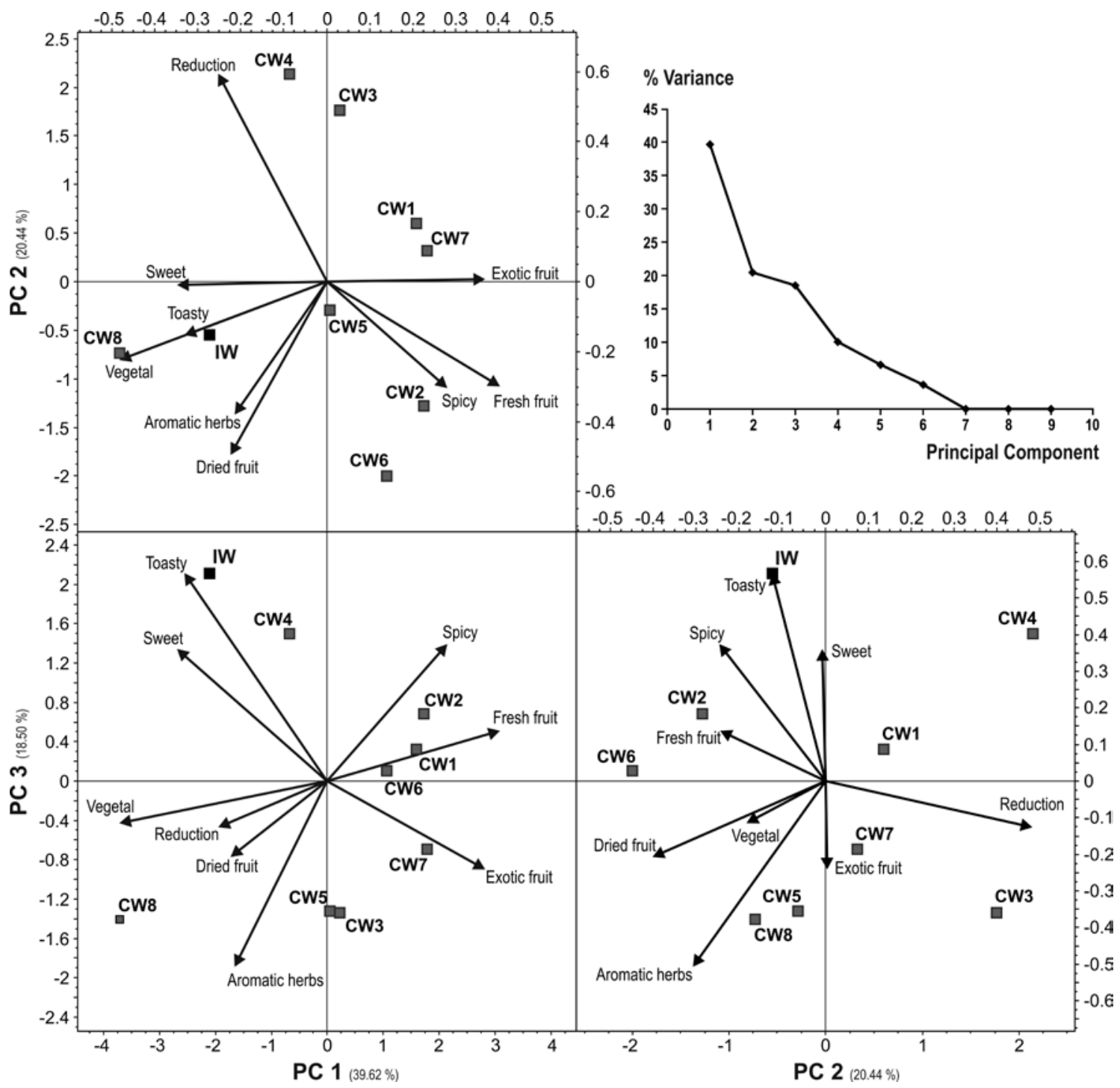

FIGURE 3

Principal component analysis (PCA) of sensorial descriptive results between the industrial wine (IW) and eight commercial rosé wines (CW1 to CW8) produced by different wineries with the Prieto Picudo grape variety. Three PCA plots, each of them formed from two PCs, are shown according to the decay graph obtained (top right), indicating that the first three PCs explained the majority of variance ( $78.56 \%$ of total variance). The scale of variables (sensory descriptor) is shown at the top and right, whereas the scale for wines is shown at the bottom and left.

since their employment in industrial fermentations could help the consumer to distinguish wines made from the same grape variety. This strategy is of great interest in a globalised wine market, where having a different bouquet and aroma is a powerful tool to commercialise wines. Wines produced in this way can be considered unique to a particular winery, and therefore we could talk about "exclusive" products, with marked differences in relation to other wines produced by other wineries in the same geographic area. Remarkably, a reduced number of strains (eight, corresponding to $6.8 \%$ ) were detected in two different wineries. The presence of yeast strains shared by different wineries at distinct locations is not unusual, since it has been reported before for other producing areas, like for the wineries of the Charentes region in France (Versavaud et al., 1995) or for Austrian wineries (Lopandić et al., 2008), among others. A single strain (C9-II, isolated in four of the five wineries) was found to be widespread in the producing area and therefore could be considered as representative of an oenological region or "terroir" (Versavaud et al., 1995). It should be noted that the yeast populations at the end of alcoholic fermentation were mainly monospecific, since $S$. cerevisiae was the only species isolated (with the only exception being the 2005 vintage from the Cooperativa Los Oteros, where a minority $2 \%$ of the total population, clone P5/7, resulted in a hybrid as reported above), but also polyclonal, since several different strains could be isolated. The microbial characterisation of spontaneous microfermentations led us to identify those strains able to dominate the fermentative process, and also strains detected in two or more wineries in at least two consecutive vintages. These strains were preselected in order to produce experimental wines, since previous reports 
indicated that dominant strains can be used to control the industrial process by obtaining homogeneous yeast populations at the end of alcoholic fermentation (Rodríguez et al., 2010).

The analysis of the killer phenotype was not a decisive factor for the final selection of strains, since many of the strains isolated at the end of the fermentative process exhibited a killer-sensitive phenotype. This data, as suggested by different studies, could indicate that the capability of killer yeast strains to eliminate sensitive strains depends on many different factors, such as the initial proportion of killer yeast with respect to the whole yeast population, the degree of susceptibility of the sensitive strains, and the treatment of the must (Pérez et al., 2001), including the presence of substances able to adsorb proteins (Van Vuuren \& Jacobs 1992), or the amount of available nitrogen (Medina et al., 1997). The wide variability of this trait observed in the strains analysed minimised the significance of using killer strains in industrial fermentations. In fact, some commercially available yeasts strains are killer sensitive, while still producing satisfactory implantation results in fermentation processes.

The characterisation of aroma volatiles in the nine experimental wines clearly showed that wines produced by different $S$. cerevisiae strains were easily distinguishable according to their aromatic profile. Since all the wines were produced from the same batch of must, we can safely assume that the aroma of the wine was clearly dependent on the yeast strains used in the fermentation process (Romano et al., 2003; Swiegers et al., 2005; Hernández-Orte et al., 2008; Swiegers et al., 2009; Álvarez-Pérez et al., 2012). It should also be pointed out that, although some authors claim that wines made with indigenous yeast strains have a better flavour profile than those made by spontaneous fermentation or by commercial yeast (Callejon et al. 2010; Cortés \& Blanco, 2010), our data indicate that this statement is not necessarily true, since, as we reported above, the R8-II and P5-XI wines showed vegetal and reduced nuances respectively that would be disliked by most of the consumers of rosé wines. Yeast strains play a crucial role in the production of volatile compounds during the fermentation process (Swiegers et al., 2005; Ferreira, 2010). The contribution of many of these compounds (ethyl esters of fatty acids and acetates of higher alcohol) to the final aroma of the wine is well established (Ferreira et al., 1995), especially when their concentrations in wines are above their corresponding thresholds. The chemical analysis of the volatile compounds clearly showed differences in the chemical composition of the wines that could partially explain the aromatic differences noted. The wine that exhibited the highest amount of esters was the C9-II sample. These quantitative results were in accordance with the results of the sensory analysis (see Fig. 2), where the C9-II wine received the maximum score for the attribute

TABLE S1

Commercial yeast strains used by all the wineries of the DO Tierra de León, and particularly for the elaboration of commercial wines CW1 to CW8, as used in the aromatic comparison with IW wine.

\begin{tabular}{lll}
\hline Commercial wine & Commercial yeast & Distributor \\
\hline CW1 & Maurivin AWRI & AB Mauri (London, England) \\
CW2 & Viniferm Diana & Agrovin (Alcazar de San Juan, Ciudad Real, Spain) \\
CW3 & Actiflore Rose & Laffort (Bordeaux Cedex. France) \\
CW4 & Actiflore Rose & Laffort (Bordeaux Cedex. France) \\
CW5 & Viniferm Diana & Agrovin (Alcazar de San Juan, Ciudad Real, Spain) \\
CW6 & IOC 18-2007 & Institut Oenologique de Champagne (Épernay, France) \\
CW7 & Actiflore Rose & Laffort (Bordeaux Cedex. France) \\
CW8 & Uvaferm BM-45 & Lallemand (Toulouse, France). \\
\hline
\end{tabular}

\section{TABLE S2}

Percentage $(\%)$ of commercial yeast strains isolated from spontaneous microvinifications with respect to the total yeast population in the five wineries analysed (three different vintages for every winery).

\begin{tabular}{llllll}
\hline & \multicolumn{5}{c}{ Winery } \\
\cline { 2 - 6 } Vintage & Gordonzello S.A. & Cooperativa Los Oteros & Pedro Casis & Cooperativa Vinícola Ribera del Cea & Vinícola Valmadrigal \\
\hline 2005 & $3.5^{\mathrm{a}}$ & ND & NA & NA & NA \\
2006 & ND & ND & ND & ND & ND \\
2007 & $1.7^{\text {a }}$ & ND & NA & ND & $65.0^{\text {a }}$ \\
2008 & NA & NA & $11.7^{\mathrm{b}}$ & ND & $41.7^{\text {a }}$ \\
2009 & NA & NA & $8.3^{\mathrm{b}}$ & NA & NA \\
\hline
\end{tabular}

ND: not detected

NA: not analysed

${ }^{a}$ Commercial yeast isolated: IOC 18-2007

${ }^{\mathrm{b}}$ Commercial yeast isolated: Uvaferm BM-45 
"fresh fruit". The selection of one particular yeast strain (C9-I) to produce an industrial wine generated a wine that exhibited attributes that were easily distinguishable in a PCA plot from the commercial wines and others elaborated with this type of grape (see Fig. 3). In fact, the industrial wine obtained the highest scores for toasty and sweet attributes, which are not easily found in the commercial rosé wines. It should be noted that, when used in microvinifications experiments, the C9-I strain produced wines dominated by spicy and fresh fruit notes (Fig. 2). These differences in the main aromatic attributes detected for the same strain could be attributed to the use of different batches of grape must, and especially to the great differences in volume and technical manipulations performed when comparing microvinification (carried out in a $500 \mathrm{~mL}$ bottle at $20^{\circ} \mathrm{C}$ ) to an industrial process (performed in a $3000 \mathrm{~L}$ stainless steel tank at $15^{\circ} \mathrm{C}$ ). Finally, it should be emphasised that the IW elaborated by using the C9-I strain produced a wine that was clearly different in its aroma profile from the classical rosé wines industrially produce by different cellars in the DO Tierra de León.

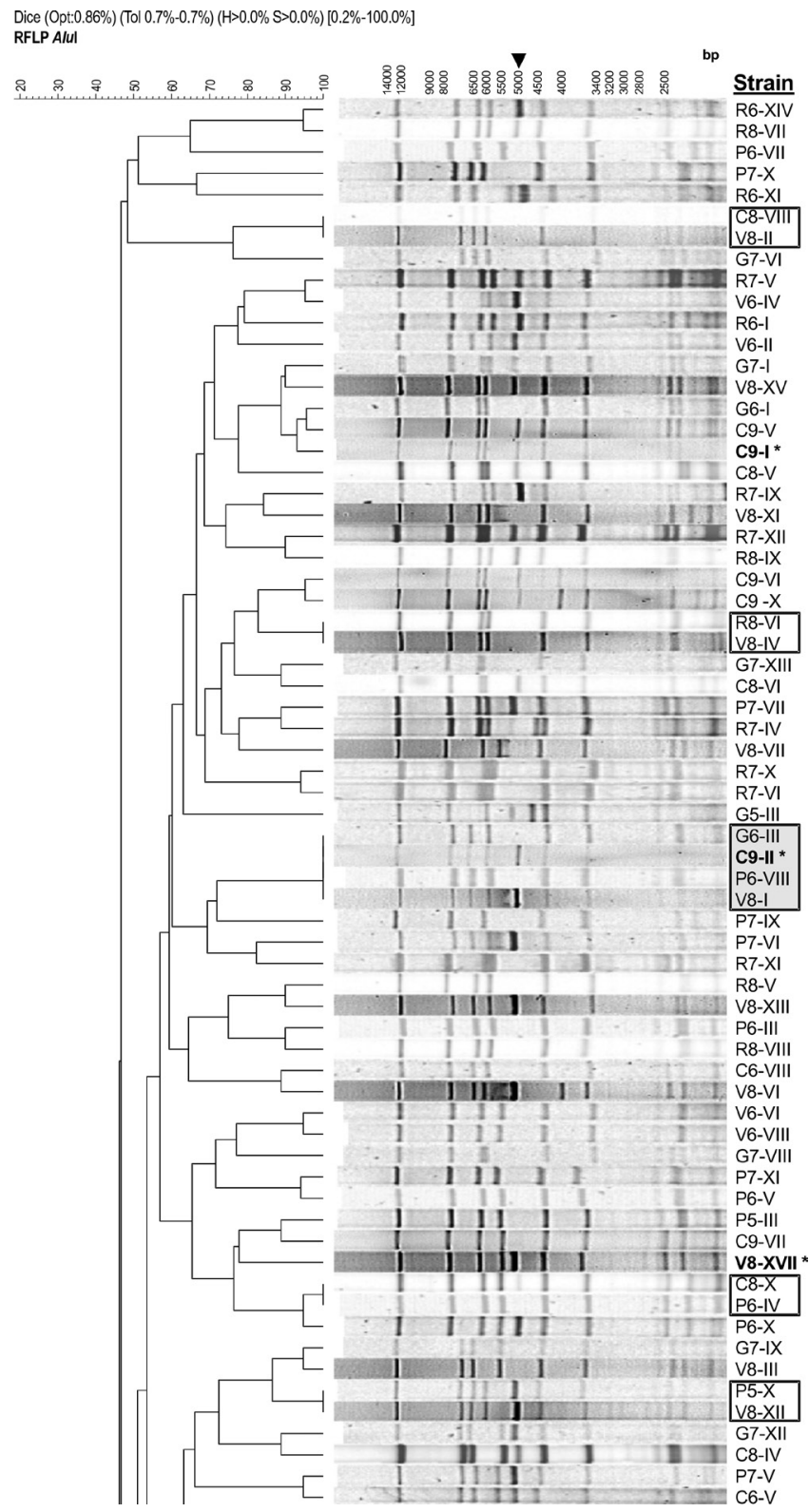

FIGURE S1 (CONTINUED)

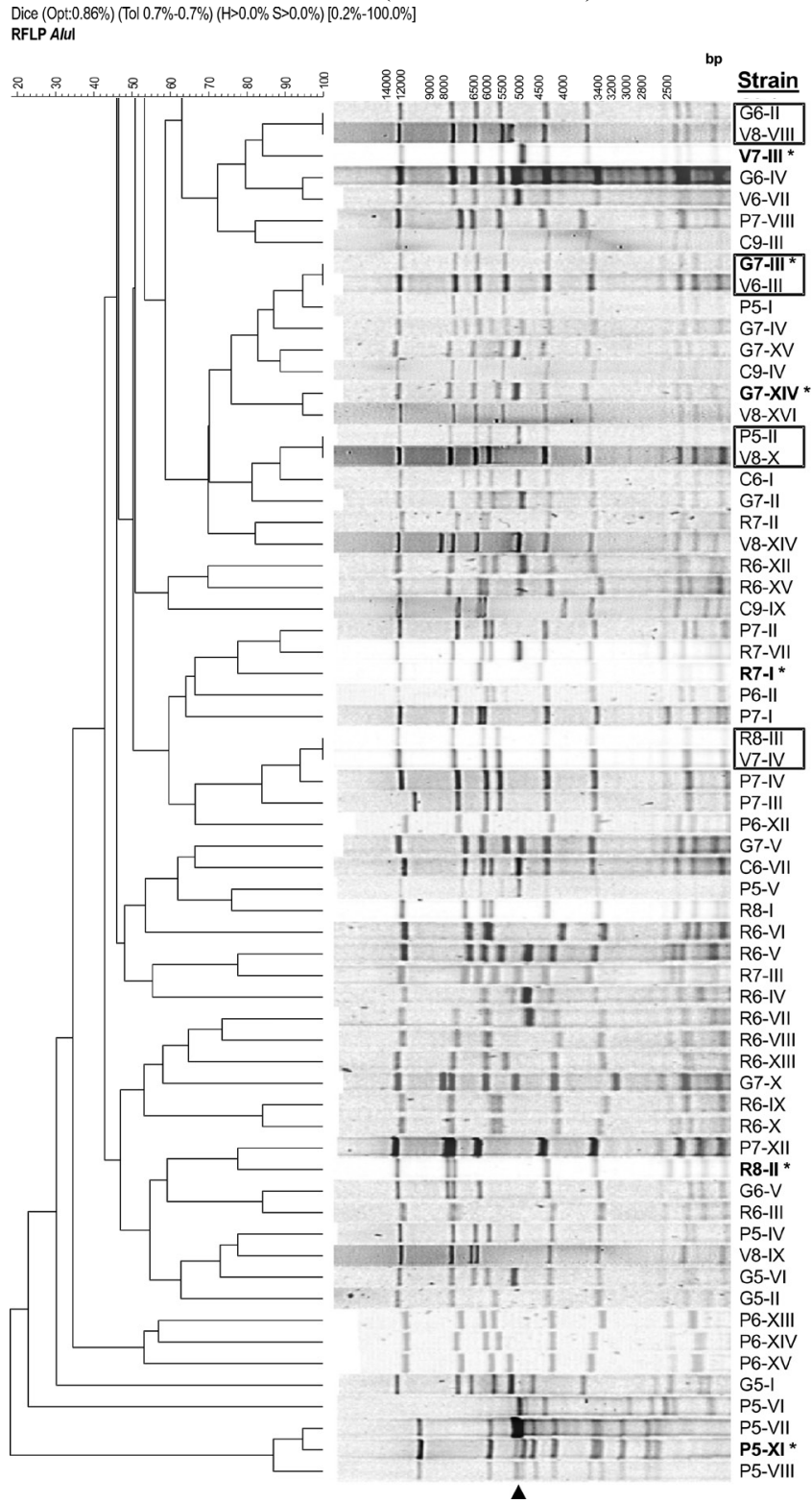

FIGURE S1

Dendrogram (left) based on RFLP-mtDNA analyses with the restriction endonuclease AluI (centre) of all the $S$. cerevisiae strains (right) isolated from the five wineries analysed. The $5 \mathrm{~kb}$ band should not be considered in the comparison (marked with an arrowhead), since it corresponds to a dsRNA of viral origin (L-A particle) that is linked with the killer phenotype (Marquina et al. 2002). Strains detected in two different wineries are highlighted by including them in boxes, whereas the only strain isolated in four different wineries is highlighted in a shaded box. The strains selected for the further oenological and aromatic characterisation are highlighted in bold and marked with an asterisk. Commercial strains detected in some of the vintages (see

Table S2 in supporting information) analysed have not been included in the dendrogram. 


\section{CONCLUSIONS}

In conclusion, each winery could produce wines with exclusive aromatic and sensorial properties by using the biotechnological approach described. This would be an excellent strategy for introducing variability in a highly competitive market.

\section{LITERATURE CITED}

Álvarez-Pérez, J.M., Campo, E., San-Juan, F., Coque, J.J.R., Ferreira, V. \& Hernández-Orte, P., 2012. Sensory and chemical characterisation of the aroma of Prieto Picudo rosé wines: The differential role of indigenous yeast strains on aroma profiles. Food Chem. 133, 284-292.

Arroyo-López, F.N., Salvadó, Z., Tronchoni, J., Guillamón, J.M., Barrio, E. \& Querol, A., 2010. Susceptibility and resistance to ethanol in Saccharomyces strains isolated from wild and fermentative environments. Yeast 27, 1005-1015.

Beltran, G., Torija, M.J., Novo, M., Ferrer, N., Poblet, M., Guillamón, J.M., Rozès, N. \& Mas, A., 2002. Analysis of yeast populations during alcoholic fermentation: A six year follow-up study. Syst. Appl. Microbiol. 25, 287293

Callejon, R.M., Clavijo, A., Ortigueira, P., Troncoso, A.M., Paneque, P. \& Morales, M.L., 2010 Volatile and sensory profile of organic red wines produced by different selected indigenous and commercial Saccharomyces cerevisiae strains. Anal. Chim. Acta 660, 68-75.

Campo, E., Ferreira, V., Escudero, A., \& Cacho, J., 2005. Prediction of the wine sensory properties related to grape variety from dynamic-headspace gas chromatography-olfactometry data. J. Agric. Food Chem. 53, 56825690 .

Cappello, M.S., Bleve, G., Grieco, F., Dellaglio, F. \& Zacheo, G., 2004. Characterization of Saccharomyces cerevisiae isolated from must of grape grown in an experimental vineyard. J. Appl. Microbiol. 97, 1274-1280.

Constanti, M., Poblet, M., Arola, L., Mas, A. \& Guillamon, J.M., 1997. Analysis of yeast populations during alcoholic fermentation in a newly established winery. Am. J. Enol. Vitic. 48, 339-344.

Corison, C.A., Ough, C.S., Berg, H.W. \& Nelson, K.E., 1979. Must aceticacid and ethyl-acetate as mold and rot indicators in grapes Am. J. Enol. Vitic. 30, 130-134

Cortés, S. \& Blanco, P., 2010. Yeast strain effect on the concentration of major volatile compounds and sensory profile of wines from Vitis vinifera var. Treixadura. World J. Microb. Biot. 27, 925-932.

Degre, R., Thomas, D.Y., Ash, J., Mailhiot, K., Morin, A. \& Dubord, C., 1989. Wine yeasts strain identification. Am. J. Enol. Vitic. 40, 309-315.

Dravnieks, A., 1985. Atlas of odor character profiles. ASTM, Philadelphia.

Esteve-Zarzoso, B., Belloch, C., Uruburu, F. \& Querol, A., 1999. Identification of yeasts by RFLP analysis of the 5.8S rRNA gene and the two ribosomal internal transcribed spacers. Int. J. Syst. Bacteriol. 49, 329-337.

Ferreira, V., 2010. Volatile aroma compounds and wine sensory attributes. In: Reynolds, A. (ed.). Managing wine quality. Viticulture and Wine Quality, Vol. 1. Woodhead Publishing Series in Food Science, Technology and Nutrition No. 187. Brock University, Canada. pp. 3 - 28

Ferreira, V., Fernández, P., Peña, C., Escudero, A. \& Cacho, J., 1995. Investigation on the role played by fermentation esters in the aroma of young Spanish wines by multivariate analysis. J. Sci. Food Agric. 67, 381-392.

Gallego, F.J., Pérez, M.A., Núñez, Y. \& Hidalgo, P., 2005. Comparison of RAPDs, AFLPs and SSR markers for the genetic analysis of yeast strains of Saccharomyces cerevisiae. Food Microbiol. 22, 561-568.
González, S.S., Barrio, E., Gafner, J. \& Querol, A., 2006. Natural hybrids from Saccharomyces cerevisiae, Saccharomyces bayanus and Saccharomyces kudriavzevii in wine fermentations. FEMS Yeast Res. 6, 1221-1234.

Hernández-Orte, P., Cersosimo, M., Loscos, N., Cacho, J., Garcia-Moruno, E. \& Ferreira, V., 2008. The development of varietal aroma from non-floral grapes by yeasts of different genera. Food Chem. 107, 1064-1077.

Legras, J.-L. \& Karst, F., 2003. Optimisation of interdelta analysis for Saccharomyces cerevisiae strain characterization. FEMS Microbiol. Lett. 221, 249-255.

Lodder, J., 1970. The yeasts, a taxonomic study. North Holland Publishing Company, Amsterdam.

Lopandić, K., Tiefenbrunner, W., Gangl, H., Mandl, K., Berger, S., Leitner, G., Abd-Ellah, G.A., Querol, A., Gardner, R.C., Sterflinger, K. \& Prillinger, H., 2008. Molecular profiling of yeasts isolated during spontaneous fermentations of Austrian wines. FEMS Yeast Res. 8, 1063-1075.

Lopes, C.A., Lavalle, T.L., Querol, A. \& Caballero, A.C., 2006. Combined use of killer biotype and mtDNA-RFLP patterns in a Patagonian wine Saccharomyces cerevisiae diversity study. Antonie Van Leeuwenhoek 89, 14756.

López, R., Aznar, M., Cacho, J. \& Ferreira, V., 2002. Determination of minor and trace volatile compounds in wine by solid-phase extraction and gas chromatography with mass spectrometric detection. J. Chromatogr. A. 966, 167-177.

López, V., Querol, A., Ramón, D. \& Fernández-Espinar, M.T., 2001. A simplified procedure to analyse mitochondrial DNA from industrial yeasts. Int. J. Food Microbiol. 68, 75-81.

Loscos, N., Hernandez-Orte, P., Cacho, J. \& Ferreira, V., 2007. Release and formation of varietal aroma compounds during alcoholic fermentation from nonfloral grape odorless flavor precursors fractions. J. Agr. Food Chem. 55, 6674-6684.

Marquina, D., Santos, A. \& Peinado, J.M., 2002. Biology of killer yeasts. Int. Microbiol. 5, 65-71.

Martini, A. \& Vaughan-Martini, A., 1990. Grape must fermentation: past and present. In: Spencer, J.F.T. \& Spencer, D.M. (eds). Yeast technology. Springer, Berlin. pp $105-123$.

Medina, K., Carrau, F.M., Gioia, O. \& Bracesco, N., 1997. Nitrogen availability of grape juice limits killer yeast growth and fermentation activity during mixed-culture fermentation with sensitive commercial yeast strains. Appl. Environ. Microbiol. 63, 2821-2825.

Nikolaou, E., Soufleros, E.H., Bouloumpasi, E. \& Tzanetakis, N., 2006 Selection of indigenous Saccharomyces cerevisiae strains according to their oenological characteristics and vinification results. Food Microbiol. 23, 205-211.

O’Donnel K., 1993. Fusarium and its near relatives. In: Reynolds, D.R. \& Taylor, J.W. (eds). The fungal holomorph: Mitotic, meiotic and pleomorphic speciation in fungal systematics. CAB International, Wallingford, UK. pp. $225-233$.

OIV (Office International de la Vigne et du Vin), 1979. Recopilación de los métodos internacionales de análisis de vinos. Publicaciones del Ministerio de Agricultura, Secretaria General Técnica, Servicio de Publicaciones Agrarias, Spain

Ortega, C., López, R., Cacho, J. \& Ferreira, V., 2001. Fast analysis of important wine volatile compounds development and validation of a new method based on gas chromatographic-flame ionisation detection analysis of dichloromethane microextracts. J. Chromatogr. A 923, 205-214.

Pérez, F., Ramírez, M. \& Regodón, J.A., 2001. Influence of killer strains of Saccharomyces cerevisiae on wine fermentation. Antonie Van Leeuwenhoek 79, 393-399. 
Peris, D., Belloch, C., Lopandić, K., Álvarez-Pérez, J.M., Querol, A. \& Barrio, E., 2012. The molecular characterization of new types of $S$. cerevisiae x $S$. kudriavzevii hybrid yeast unveils a high genetic diversity. Yeast 29, 81-91.

Pretorius, I.S., 2000. Tailoring wine yeast for the new millennium: Novel approaches to the ancient art of winemaking. Yeast 16, 675-729.

Querol, A. \& Bond, U., 2009. The complex and dynamic genomes of industrial yeasts. FEMS Microbiol. Lett. 293, 1-10.

Querol, A., Barrio, E. \& Ramón, D., 1992b. A comparative study of different methods of yeast strain characterization. System Appl. Microbiol. 15, 439446.

Querol, A., Barrio, E., Huerta, T. \& Ramón, D., 1992a. Molecular monitoring of wine fermentations conducted by active dry yeasts strains. Appl. Environ. Microbiol. 58, 2948-2953.

Rodríguez, M.E., Infante, J.J., Molina, M., Domínguez, M., Rebordinos, L. \& Cantoral, J.M., 2010 Genomic characterization and selection of wine yeast to conduct industrial fermentations of a white wine produced in a SW Spain winery. J. Appl. Microbiol. 108, 1292-1302.

Rodríguez-Cousino, N., Maqueda, M., Ambrona, J., Zamora, E., Esteban, R. \& Ramirez, M., 2011. A new wine Saccharomyces cerevisiae killer toxin (Klus), encoded by a double-stranded RNA virus, with broad antifungal activity is evolutionarily related to a chromosomal host gene. Appl. Environ. Microbiol. 77, 1822-1832.

Romano, P., Fiore, C., Paraggio, M., Caruso, M. \& Capece, A., 2003. Function of yeast species and strains in wine flavour. Int. J. Food Microbiol. 86, 169-180.
Sangorrín, M.P., Zajonskovsky, I.E., Lopes, C.A., Rodríguez, M.E., Giraudo de van Broock, M.R. \& Caballero, A.C., 2001. Killer behaviour in wild wine yeasts associated with Merlot and Malbec type musts spontaneously fermented from northwestern Patagonia (Argentina). J. Basic Microbiol. 41, 105-113.

Swiegers, J., Bartowsky, E., Henschke, P. \& Pretorius, I.S., 2005. Yeast and bacterial modulation of wine aroma and flavour. Aust. J. Grape Wine R. 11, 139-173.

Swiegers, J.H., Kievit, R.L., Siebert, T., Lattey, K.A., Bramley, B.R., Francis, I.L., King, E.S. \& Pretorius, I.S., 2009. The influence of yeast on the aroma of Sauvignon Blanc wine. Food Microbiol. 26, 204-211.

Van Vuuren, H.J.J. \& Jacobs, C.J., 1992. Killer yeasts in the wine industry: A review. Am. J. Enol. Vitic. 43, 119-128.

Versavaud, A., Courcoux, P., Roulland, C., Dulau, L., \& Hallet, J.N., 1995. Genetic diversity and geographical distribution of wild Saccharomyces cerevisiae strains from the wine-producing area of Charentes, France. Appl. Environ. Microbiol. 61, 3521-3529.

White, T.J., Bruns, T., Lee, S. \& Taylor, J., 1990. Amplification and direct sequencing of fungal ribosomal RNA genes for phylogenetics. In: Innis, M.A., Gelfand, D.H., Sninsky, J.J. \& White, T.J. (eds). PCR protocols: A guide to methods and applications. Academic Press, San Diego. pp. 315 -322 .

Zwietering, M.H., Jongerburger, I., Rombouts, F.M. \& Van't Riet, K., 1990. Modeling of the bacteria growth curve. Appl. Environ. Microbiol. 56, 18751881. 